\title{
COMPARATIVE STUDY BETWEEN OSSEOINTEGRATION AROUND NANOSTRUCTURE IMPLANT AND SANDBLASTED IN IMMEDIATE PLACEMENT (EXPERIMENTAL STUDY)
}

\begin{abstract}
Aya F. Barakat ${ }^{1}$ BDS, Ahmed S. El-Mahallawy² PHD, Tarek M. Aly³ PHD, Sahar K. Shafik
${ }^{4} \mathrm{PHD}$

\section{ABSTRACT}

INTRODUCTION: The quality of the implant surfaces is one of the major factors that influences wound healing at the implantation site and subsequently affects osseo-integration.

OBJECTIVES: Evaluation of the osseo-integration around nano-structured dental implant and around sandblasted type histologically.

MATERIALS AND METHODS: This experimental study was done on 6 healthy mongrel dogs, all dogs were healthy as documented by a veterinarian report, and kept under the same nutritional and environmental conditions in the animal house at the Physiology Department, Faculty of Medicine, Alexandria University. All dogs were divided into 2 groups: group A received nanostructured dental implant in the left side, group B received sandblasted dental implant in the right side. Afterwards the dogs were sacrificed at 3 and 6 weeks after implant insertion. RESULTS In group A the osseo integration of all implants was noted. New bone formed in direct contact with the implant surfaces and the threads. But in group B one experimental animal preserved the implant in its place while the others were displaced from the bone with fibrous tissue interface.
\end{abstract}

CONCLUSIONS: There is significant increase in the bone healing around nano dental implants as opposed to sandblasted implants. KEYWORDS: Osseo integration, Nano dental implants, sandblasting implants, immediate implant, experimental study.

1-BDS, Oral and Maxillofacial Surgery Department, Faculty of Dentistry, Alexandria University, Egypt. 2-Professor of Oral and Maxillofacial Surgery, Faculty of Dentistry, Alexandria University, Egypt.

3-Professor of Oral and Maxillofacial Surgery and Dean of Faculty of Dentistry, Alexandria University, Egypt. 4-Head of Oral Biology Department, Faculty of Dentistry, Alexandria University, Egypt.

\section{INTRODUCTION}

Dental implants have become a treatment option widely used for the replacement of lost teeth. The development of dental and the implant supported oral restoration has become an increasingly used treatment option for partially edentulous and completely edentulous patients (1).

The term osseo-integration has been successively redefined, the common denominator being an inanimate metallic structure anchored long-term in living bone under functional loading (2). Osseointegration histologically, defined as "Direct anchorage of an implant by the formation of bone directly on the surface of the implant with or without intervening layer of fibrous tissue" (3).

Nowadays, commercially pure (cp) titanium and its alloys are the materials most often used in implant manufacturing because of their excellent biocompatibility, favorable mechanical properties and well-documented beneficial results. When exposed to air titanium immediately develops a stable oxide layer, which forms the basis of its exceptional biocompatibility. The properties of the oxide layer, i.e. its chemical purity and surface cleanliness, are of great importance for the biological outcome of the osseo-integration of titanium implants (4).

A satisfactory clinical outcome relies on the ability of the implant to bear loads, which is a function of the primary stability immediately following implantation but is dependent on solid osseointegration of the implant into the host bone for the long term (5).
An essential role of osseointegration processes is played by osteoblast progenitor stem cells during recruitment, adhesion, proliferation, differentiation and mineralized matrix deposition during bone regeneration phases $(6,7)$.

When implant placement is planned before extraction of the tooth, consideration should be given to the most desirable time for implant placement. Implant may be placed immediately, early or late (8).

The benefit of immediate implantation can be summarized as: healing time will be reduced by combining integration of the dental implant with mineralization of the socket. Preservation of ridge dimensions by the presence of the dental implant and so minimizing the amount of bone resorption. Preservation of soft tissue contour and enhanced esthetics. Position and angulation of the implant will be directed by the walls of the recently extracted tooth socket (9).

According to Albrektsson et al (10). the quality of the implant surfaces is one major factor that influences wound healing at the implantation site and subsequently affects osseointegration. It is commonly thought that the slightly roughened implant surface allows better osseointegration compared with the smooth implant surface $(11,12)$. Moreover nanostructured materials have shown increased cell attachment over micro structured or smooth surfaces $(13,14)$.

Nanoporous topography tend to help the proliferation processes, acting directly on the selective adhesion of osteoblastic cells on the surface, which can accelerate the 
healing process around implants $(15,16)$. Low osteoblasts cell number and proliferation have been closely associated with negative results when considering it to osseointegration $(17,18)$.

In this study, there were two commercially available implants, A nanostructured processed implant formed by noble gas ion bombardment and the other had sandblasted, large grit, acid-etched surface. Thereafter, the two commercially available implants were placed in the lower jaw of dogs to observe histologically the bone healing at three and six weeks.

\section{MATERIALS AND METHODS}

This study was approved by the ethical committee of the Faculty of Dentistry, Alexandria University.

This experimental animal study was carried out at animal house in the Physiology Department, Faculty of Medicine, Alexandria University.

The sample consisted of 6 healthy mongrel dogs, about 18-24 months old, and with average weight of 9-13 kg. All dogs were healthy as documented by a veterinarian report, and kept under the same nutritional and environmental conditions. Each dog received bilateral implants as immediate implantation with total of 12 implants divided into groups:

Study group A: consisted of 6 dogs which had extraction of mandibular left premolar and nanostructured implant (PI) was inserted immediately.

Control group B: consisted of 6 dogs which had extraction of mandibular right premolar and sandblasted implant (TRI) was inserted immediately.

\section{The implant system}

\section{Nano Structured P-I implant}

Professor Per-Ingvar Brånemark (P-I) Amplified Functional Hybrid Implants with a diameters of (3.3,) mm and lengths of (10) mm (Zimmer Biomet, Poland), which had feature simplified conical surgical preparation, platform-switching connections, and a micro and nanostructured, minimally roughened surface by blasted and ion bombarded.

\section{Sandblasted TRI implant}

Through Research Innovative (TRI) which has large grit, sandblasted and acid etched surfaces with the same diameters and lengths developed in the Switzerland, which had sandblasted, large grit, acid-etched surface.

\section{Methods}

\section{Pre-operative phase}

The animals were examined by the animal house veterinarian to exclude any diseased animal. All dogs were kept under the same environmental condition. Every dog was kept in a separate cage to avoid trauma to the surgical site. All dogs received the same balanced soft diet through the period of the study (Milk, soft meat, broth). All animals received a dose of antibiotic intramuscularly: ampicillin 25/kg (Amoxil $250 \mathrm{mg} / 5 \mathrm{ml}$, Glaxo Smith Kline) just before the operation.

\section{Operative Phase}

\section{A-Anesthesia:}

The animals were generally anesthetized via intravenous injection of Sodium Thiopentone (Thiopental Sodium 50 mg, by Egyptian Int. Pharmaceutical Industries Co. EIPICO, 10th of Ramadan City, Egypt). The dose of which was calculated on basis of $30 \mathrm{mg} / \mathrm{kg}$ body weight.

\section{B-The Operative procedure}

The oral mucosa was painted and rubbed thoroughly with antiseptic Povidone Iodine (Betadine, The Nile Co. for Pharma, Cairo, Egypt). Solution $10 \%$ so as to render the surgical field free from microorganisms. The lower left premolar tooth was extracted with minimal trauma using a lower premolar forceps. Drilling with the osteotomy drill mounted on low speed hand piece was done in the socket under cooling with sterile saline irrigation. A pumping motion was used while drilling to allow the osseous debris to be cleared from the site. The implant was inserted into the prepared socket with the vial cap and turned in a clockwise direction with slight apical pressure to gain stability of the implant in its position till difficulty is encountered, and then the vial cap was removed. For final seating of the implant in bone; the Ratchet driver combined with the hex driver was mounted onto the implant, and used till the implant body was flushed with the level of alveolar crest of bone. Wrenching was carried out in only a horizontal plane, and care was taken to avoid movements in any other planes, not to widen the osteotomy. The cover screw was then placed on top of the implant using the finger driver. An interrupted suture was done to approximate the gingival margins using 3-0 resorbable suture material. The same procedure was carried on the right side with exchange P-I implant by TRI implant (Figure 1).

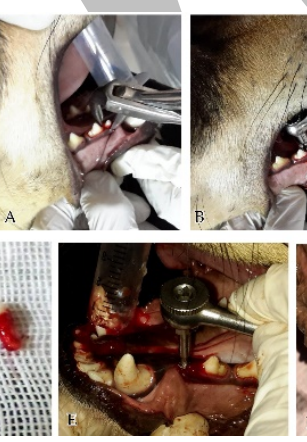

Figure 1:

(A) Extraction of lower right premolar tooth.

(B) TRI implant insertion.

(C) Implant after fixation in the socket immediately.

(D) Two premolar teeth after extraction.

(E) P-I implant insertion in the other side

(F) Two implant inside the oral cavity.

(G) Wound closure after implant insertion

\section{Postoperative phase}

\section{Clinical follow up period}

Animals received a dose of ampicillin $25 \mathrm{mg} / \mathrm{kg}$ body weight (Amoxil $250 \mathrm{mg} / 5 \mathrm{ml}$, Glaxo Smith Kline) by intravenous injection just after the operation. Dogs received a dose of amoxicillin 500mg (Amoxil provided by: Medical-union pharmaceuticals, Abu-Sultan, Ismailia, Egypt) every 24 hours for 5 days post-operatively.

The dogs received non-steroidal anti-inflammatory and analgesic in the form of diclofenac potassium 25mg (Cataflam, Novartis pharma, Cairo, Egypt) every 24 hours for 3 days. The animals were kept under observation to assess the presence or absence of any infection or any arising complications. Animals were kept on soft diet during the first few weeks postoperatively.

\section{Animal sacrification}


Three Dogs were sacrificed at 3 and 6 weeks postoperatively by giving them an overdose of thiopentone sodium intravenously. Segments containing the implants and the adjacent bone were retrieved to be prepared for histological examination. They were immediately immersed in $10 \%$ neutral buffered formalin for fixation.

\section{Composition of the neutral buffered formalin:}

\section{$37-40 \%$ formalin}

Distilled water

Sodium phosphate monobasic

Sodium phosphate dibasic anhydrous

\section{Preparation of histological sections}

Washing: The specimens were then washed under running tap water for 6 hours to remove the excess of the fixative solution.

Undecalcification: Specimen preparation, fixation and processing were achieved with a manner similar to other soft tissues, however due to the density and lower permeability of bone considerably longer fixation and processing times were required, often taking several weeks. Embedding was achieved using a supporting medium with similar or equal hardness and density to the bone such as methacrylate- based resins, but unlike paraffin infiltration and embedding, this was an irreversible step. Sectioning was achieved by using a diamond blade on a microtome in the biomaterial department of the Faculty of Dentistry, Alexandria University.

\section{Statistical analysis}

Data were fed to the computer and analyzed using IBM SPSS software package version 20.0 (Armonk, NY: IBM Corp). Comparisons between groups for categorical variables were assessed using Chi-square test (Fisher). Qualitative data was described using number and percent. Significance of the obtained results was judged at the 5\% level.

\section{RESULTS}

\section{Clinical Results}

All animals survived well, and remained active and alert all over the course of the experiment. The animals tolerated the surgical procedure well. During the first week the animals did not exhibit any clinical signs of infection. In the third post-operative week; the clinical observation revealed that the right side of all dogs has slightly mobility but the left one has good stability. All blocks obtained from control and study groups at 3 and 6 weeks were prepared for histological evaluation.

\section{Histological Results}

In group A: After 3 weeks all the implants appeared osseointegrated, the experimental site was completely filled with granulation tissues and woven bone formation at the interface of the socket and the implant. The newly formed bone was in close contact with the implant surfaces, and extended between the threads of the implants. (Figure 2)

In group A: After 6 weeks the osseointegration of all implants was noted. New bone formed in direct contact with the implant surfaces and the threads. This bone presented newly formed osteons and remodeling of the bone was started to replace the immature bone by well-organized mature bone. In some areas bone apposition and remodeling was not clearly remarked. (Figure 3)

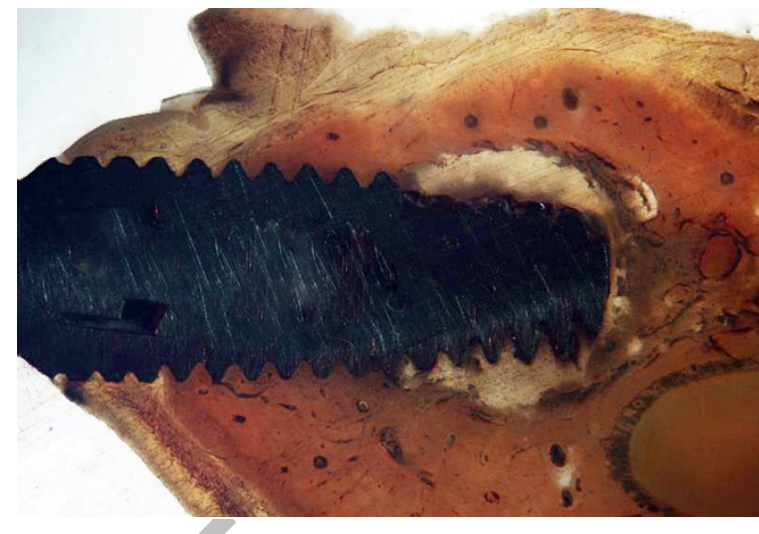

Figure 2: Undecalcified section showing the experimental site was filled with granulation tissues and woven bone formation at the interface of the socket and the implant after 3 weeks of P-I implant insertion.

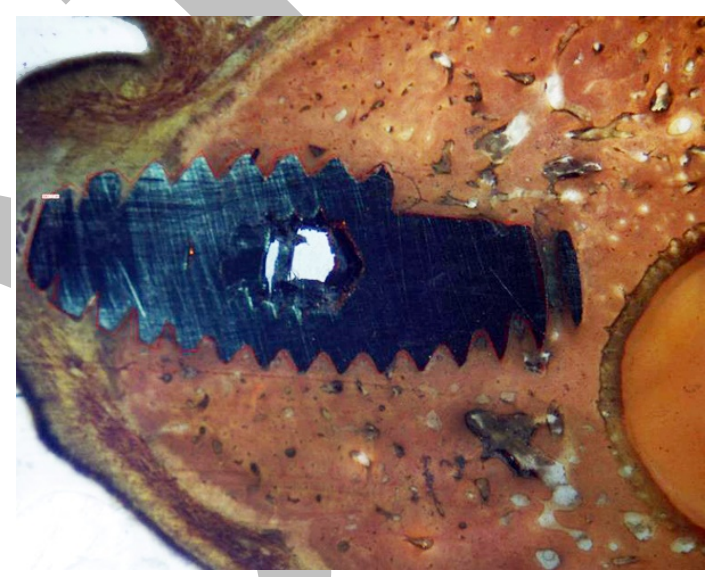

Figure 3: Undecalcified section showing newly formed osteons and remodling of the bone after 6 weeks of P-I implant insertion.

In group B: After 3 weeks in one of the experimental animals showed that the implant was in its place while the others were displaced from the bone. We found fibrous tissue interface between the implant surfaces and the native bone. As well as areas of woven bone was formed. (Figure 4)

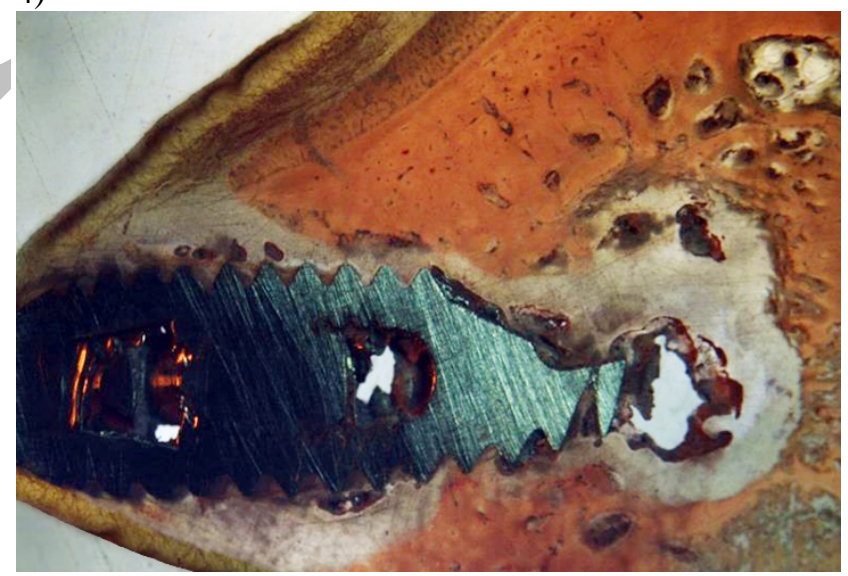

Figure 4: Undecalcified section showing fibrous tissue interface between the implant surfaces and the native bone after 3 weeks of TRI implant insertion.

In group B: After 6 weeks implants were displaced from the bone as well. The experimental site of implant was completely filled with bone which was almost mature bone with small areas were immature showing initiation of bone remodeling. (Figure 5) 


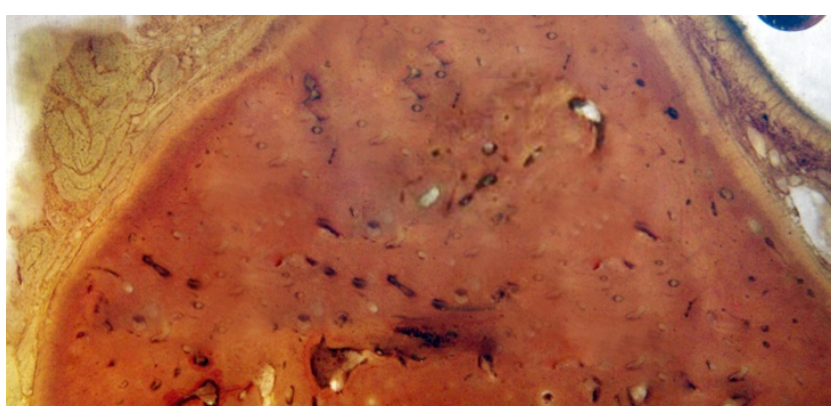

Figure 5: Undecalcified section showing the implant was displaced from the socket and the Experimental site of implant is filled with mature and immature bone after 6 weeks of TRI implant insertion.

\section{DISCUSSION}

The high success rate of titanium dental implants has been attributed to formation of a direct bone-implant interface with no intervening soft tissues (19). However, treatment of jaws with advanced resorption and poor bone quality presents a high rate of implant failure. One way to decrease this clinical problem is to use a dental implant with a treated surface, it has been suggested that physiochemical and dielectric properties, crystal structure and surface morphology of titanium oxide films on dental implant surfaces play a crucial role in the biocompatibility and osseointegration of implants (20-22).

The present study was conducted on six healthy dogs. In each dog tooth extraction were performed in both sides. the implants were placed immediately into fresh extraction sockets. The dogs were divided equally into two groups;

Group A: The animals received nanostructured implants PI in the left side of the mandible.

Group B: The animals received sandblasted implants TRI in the right side of the mandible. These dogs were sacrificed at 3 and 6 weeks postoperatively for histological evaluation of the osseointegration around sandblasted and Nano implant.

In this study the immediate implant placement protocol was used where a low speed high torque hand piece was used for the preparation of the implant bed, and the drilling was performed under profuse irrigation using cold sterile saline for proper cooling and to avoid overheating of the bone tissues which would compromise osseointegration in accordance to Strbac et al in 2014 (23).

In this study, the observations of the first experimental periods in both groups revealed that an inflammatory reaction occurred. And the experimental site was filled with granulation tissues at the interface of the socket and the implant. Bone resorption was first observed at 3 weeks in both sides but in side of Nano implant was lower than sandblasted one and gradual bone apposition in Nano side was done.

This biological sequence of bone healing observed in this study is consistent with other reports describing the early phases of wound healing in fresh extraction sockets like Cardaropoli et al. 2003(24) and Araujo \& Lindhe 2005 (25) and the healing after inserting an implant in a healed ridge Berglundh et al. 2003(26) and Abrahamsson et al. 2004(27).
In this investigation, during the third observation periods, the healing process in group A was different from that in group B due to the enhanced implant surface (PI) showed higher BIC in the healing phases. These results are consistent with those obtained by Meirelles et al. 2007, $2008 b(28,29)$ that investigated in the rabbit model the effect of hydroxyapatite nano-particles used to modify smooth titanium implant surfaces. Their results showed significant higher BIC values in the nano-HA enhanced implant surfaces.

Our results are in agreement with Williams (1999) (30) who evaluated the ability of nano-topographically complex titanium surfaces to accelerate osseoconduction and to enhance the bone-bonding phenomenon. With this purpose, different surfaces composed of commercially pure titanium (cpTi) and titanium alloy (Ti6Al4V or Ti64) with micro topographically complex surfaces have been tested. These surfaces were further modified by discrete crystalline depositions (DCD) of CaP nano-particles that were able to create a nano-topographic complexity at each implant surface. Findings from these studies which done by Mendes $(2007,2009)(31,32)$ in rats evidenced an increase in osseoconduction and a significant enhancement in the bonebonding phenomenon at the implants with an enhanced surface nano-topography.

Also, Kim et al. in 2010 (33) who studied three implants surfaces: 1. machined surface, 2. sand blasted and acid etched surface, and 3. anodic oxidized surface. They reported that implant design and surface treatment may have significant effects on biological stability 3 weeks after implant placement. Moreover, Ballo et al. in 2011 (34) studied an implantable model system to investigate the effects of nanoscale surface properties on the osseointegration of titanium implants in rat tibia. They emphasized the current results and findings where they concluded that after insertion in bone, a significant enhancement in bone formation was detected on Ti implant surfaces modified by 60 nanometers (semi-spheres) after 28 days of healing (four weeks). The results of these studies are in accordance with the results of this investigation as regards the effect of nanotechnology in enhancing bone formation.

\section{CONCLUSION}

Within this context, it can be concluded that the nanostructured implants have more significant influence on the bone healing around implants placed into fresh extraction sockets than the sandblasted implants. However, there is no statistical significant difference due to limitation of sample size.

\section{CONFLICT OF INTEREST}

No potential conflict of interest relevant to this article was reported.

\section{REFERENCES}

1-Widmann G, Bale RJ. Accuracy in computer-aided implant surgery--a review. Int J Oral Maxillofac Implants. 2006;21:305-13.

2-Triplett RG, Frohberg U, Sykaras N, Woody RD. Implant materials, design, and surface topographies: their influence on osseointegration of dental implants. J Long Term Eff Med Implants. 2003;13:485-501. 
3- Raghavendra S, Wood MC, Taylor TD. Early wound healing aroundendosseous implants: A review of literature. Int J Oral Maxillofac Implants. 2005;20:425-31.

4- Sykaras N, Iacopino AM, Marker VA, Triplett RG, Woody RD. Implant materials. A literature review. Int J Oral Maxillofacial Implants. 2000;15:675-90.

5- Sennerby L, Dasmah A, Larsson B, Iverhed M. Surfacemodified zirconia implants: A histomorphometric and removal torque study in the rabbit. Clin Implant Dent Relat Res. 2005;7(Suppl 1):S13-20.

6- Piattelli A, Piattelli M, Romasco N, Trisi P. Histochemical and laser scanning microscopy characterization of the hydroxyapatite-bone interface: an experimental study in rabbits. Int J Oral Maxillofacial Implants. 1994;9:163-8.

7- Mavrogenis AF, Dimitriou R, Parvizi J, Babis GC. Biology of implant osseointegration. J Musculoskelet Neuronal Interact. 2009;9:61-71.

8- Peterson LJ, Ellis E, Hupp JR, Tucker MR. Contemporary oral and maxillofacial surgery. 4th ed. St Louis: Mosby; 2003.

9- Lekovic V, Kenney EB, Weinlaender M. A bone regenerative approach to alveolar ridge maintenance following tooth exraction: Report of 10 cases. J Periodontal. 1997:68:563-70.

10-Albrektsson T, Branemark PI, Hansson HA, Lindstrom J. Osseointegrated titanium implants. Requirements for ensuring a long-lasting, direct bone-to-implant anchorage in man. Acta Orthop Scand. 1981;52:155-70.

11-Fan Z, Jia S, Su JS. Influence of surface roughness of titanium implant on core binding factor alpha 1 subunit of osteoblasts. Zhonghua Kou Qiang Yi Xue Za Zhi. 2010;45:466-70.

12-Jager M, Zilkens C, Zanger K, Krauspe R. Significance of nano- and microtopography for cell- surface interactions in orthopaedic implants. J Biomed Biotechnol. 2007;2007:69036.

13-Webster TJ, Schadler LS, Siegel RW, Bizios R. Mechanisms of enhanced osteoblast adhesion on nanophase alumina involve vitronectin. Tissue Eng. 2001;7:291-301.

14-Webster TJ, Ejiofor JU. Increased osteoblast adhesion on nanophase metals: Ti, Ti6A14V, and CoCrMo. Biomaterials. 2004;25:4731-9.

15-Le Guehennec L, Soueidan A, Layrolle P, Amouriq Y. Surface treatments of titanium dental implants for rapid osseointegration. Dent Mater. 2007;23:844-54.

16-De Oliveira PT, Nanci A. Nanotexturing of titanium-based surfaces upregulates expression of bone sialoprotein and osteopontin by cultured osteogenic cells. Biomaterials. 2004;25:403-13.

17-Aita H, Hori N, Takeuchi M, Suzuki T, Yamada M, Anpo M, Ogawa T. The effect of ultraviolet functionalization of titanium on integration with bone. Biomaterials. 2009;30:1015-25.

18-Saito T, Hayashi H, Kameyama T, Hishida M, Nagai K, Teraoka K, et al. Suppressed proliferation of mouse osteoblast-like cells by a rough surfaced substrate leads to low differentiation and mineralization. Mater Sci Eng C Mater Biol Appl. 2010;30:1-7.

19-Adell R, Eriksson B, Lekholm U, Branemark PI, Jemt T. Long-term follow-up study of osseointegrated implants in the treatment of totally edentulous jaws. Int J Oral Maxillofac Implants. 1990;5:347-59.
20-Bowers KT, Keller JC, Randolph BA, Wick DG, Michaels CM. Optimization of surface micromorphology for enhanced osteoblast responses in vitro. Int $\mathrm{J}$ Oral Maxillofac Implants. 1992; 7:302-10.

21- Martin JY, Schwartz Z, Hummert TW, Schraub DM, Simpson J, Lankford J Jr, et al. Effect of titanium surface roughness on proliferation, differentiation, and protein synthesis of human osteoblast-like cells (MG63). J Biomed Mater Res. 1995; 29:389-401.

22- Cochran DL, Schenk RK, Lussi A, Higginbottom FL, Buser D. Bone response to unloaded and loaded titanium implants with sandblasted and acid-etched surface: A histometric study in the canine mandible. J Biomed Mater Res. 1998; 40:1-11.

23- Strbac GD, Unger E, Donner R, Bijak M, Watzek G, Zechner W. Thermal effects of a combined irrigation method during implant site drilling. A standardized in vitro study using a bovine rib model. Clin Oral Implants Res. 2014; 25: 665-74.

24-Cardaropoli G, Araujo M, Lindhe J. Dynamics of bone tissue formation in tooth extraction sites. An experimental study in dogs. J Clin Periodontol. 2003;30:809-18.

25-Araujo MG, Lindhe J. Dimensional ridge alterations following tooth extraction. An experimental study in the dog. J Clin Periodontol. 2005;32:212-8.

26-Berglundh T, Abrahamsson I, Lang NP, Lindhe J. De novo alveolar bone formation adjacent to endosseous implants. Clin Oral Implants Res. 2003;14:251-62.

27-Abrahamsson I, Berglundh T, Linder E, Lang NP, Lindhe J. Early bone formation adjacent to rough and turned endosseous implant surfaces. An experimental study in the dog. Clin Oral Implants Res. 2004;15:381-92.

28- Meirelles L, Arvidsson A, Albrektsson T, Wennerberg A. Increased bone formation to unstable nano rough titanium implants. Clin Oral Implants Res. 2007;18:32632.

29- Meirelles L, Arvidsson A, Andersson M, Kjellin P, Albrektsson T, Wennerberg A. Nano hydroxyapatite structures influence early bone formation. J Biomed Mater Res A. 2008;87:299-307.

30-Williams D. The Williams Dictionary of Biomaterials. Liverpool: Liverpool University Press; 1999.

31-Mendes VC, Moineddin R, Davies JE. The effect of discrete calcium phosphate nanocrystals on bone-bonding to titanium surfaces. Biomaterials. 2007;28:4748-55.

32- Mendes VC, Moineddin R, Davies JE. Discrete calcium phosphate nanocrystalline deposition enhances osteoconduction on titanium-based implant surfaces. J Biomed Mater Res A. 2009;90:577-85.

33- Kim SJ, Kim MR, Rim JS, Chung SM, Shin SW. Comparison of implant stability after different implant surface treatments in dog bone. J Appl Oral Sci. 2010; 18: 415-20.

34- Ballo A, Agheli H, Lausmaa J, Thomsen P, Petronis S. Nanostructured model implants for in vivo studies: influence of well-defined nanotopography on de novo bone formation on titanium implants. Int J Nanomedicine. 2011; 6:3415-28. 